\title{
Photographed Metaphors: Meaning, Reference, and Translation in Manoel de Barros
}

\author{
Axel Pérez Trujillo Diniz \\ University of Alberta, Edmonton
}

This article explores Brazilian poet Manoel de Barros' collaboration with photographer Adriana Lafer in Arquitetura do silêncio (2015). The meta discourse on language that emerges in the book challenges meaning, reference, and translation as a means to transfigure the modes of seeing the Pantanal biome in Brazil, shifting our focus to the insignificant and abandoned things strewn across the ground. By tracing the contributions of Frege and Quine in tandem with Barros' playful questioning of how words represent the world around us, this article argues in favour of profound awareness of language in the Brazilian poet's work, an awareness that culminates in the blurring of words and images in Arquitetura. 